\title{
Observations from Wuhan: An Adaptive Risk and Crisis Communication System for a Health Emergency
}

\author{
Hui Zhang ${ }^{1,2}$ \\ Yingxiang $\mathrm{Li}^{1}$ \\ Chris Dolan (iD) \\ Zhijun Song '
}

'School of Public Administration, Guangzhou University, Guangzhou, People's Republic of China; ${ }^{2}$ Institute for Risk \& Disaster Reduction, University College London, London, UK; ${ }^{3}$ Institute of Advanced Studies, University College London, London, UK
Correspondence: Chris Dolan Institute of Advanced Studies, University College London, London, UK Tel +4402076792000

Email Chris.Dolan@cantab.net
Purpose: With the rapid spread of COVID-19 across the world, the consideration of effective communication strategies from Wuhan can provide valuable insight to other countries in how to manage their risk response. This study analyzes the building of a risk communication system in Wuhan, China, to aid cross-country comparison from a policy and academic perspective.

Methods: We use complex adaptive systems theory (CAS) to theorize the communication strategy adopted by the government - led by the Hubei Province COVID-19 Epidemic Prevention and Control Headquarters. Using ethnographic fieldwork and discourse analysis, we observed and analyzed the online and offline communication process to formulate an overview of the communications platforms used in Wuhan.

Results: Wuhan's adaptive crisis communication system was backed by digital and offline infrastructure, human resources support, policy development, as well as access to scientific and technological expertize. The Wuhan municipal government adapted its communication strategy in response to public feedback, and created mechanisms to ensure that two-way communication was used to drive policy and integrate feedback from the government, enterprises, social organizations and the public. Wuhan's risk and crisis communication strategy aimed to meet emergency commitments, recover trust, regulate the public's emotions and build consensus, operating within a complex adaptive system (CAS).

Conclusion: By using complex adaptive system (CAS) theory, we argue that Wuhan quickly built an adaptive communication system consisting of five elements: 1) non-linear information output, 2) online and offline continuous support systems, 3) a public emotional support system, 4) multi-subject information interaction platforms and 5) a context-based approach.

Keywords: epidemic, complex adaptive system, Wuhan, lockdown, pandemic, COVID-19

\section{Introduction}

As the city at the center of the COVID-19 outbreak, Wuhan was the first area to "lockdown" for 77 days from January 23, 2020, a strategy that was subsequently adopted by other countries as the novel coronavirus spread. The development of COVID-19 brought severe challenges to the emergency management system in Wuhan (the capital city of the Hubei province), as well as across the Hubei province. As of May 28, 2020, Wuhan had reported 50,006 confirmed cases of COVID-19, accounting for $74 \%$ of the total confirmed cases in Hubei province, and $61 \%$ of the total confirmed cases in China. ${ }^{1}$ 
During the lockdown, public health measures were taken across China - 345 cities (of a total of 686)closed schools, quarantined suspected and confirmed patients, and published daily information on public health. 220 cities $(64.3 \%)$ closed entertainment venues and banned public gatherings, 136 cities (39.7\%) suspended municipal public transportation, and 219 cities (64\%) banned intercity travel. ${ }^{2}$

The failed lockdown attempt for Ebola by the Libyan government in 2014 led to violent protests. ${ }^{3}$ In contrast, Wuhan's lockdown saw high levels of compliance and no protests by Wuhan's residents. The government stated that their "firm decision" to lockdown reduced the total number of COVID-19 cases in China by $96 \%$ and helped mitigate panic. ${ }^{4}$ What lessons are learned from Wuhan's lockdown response in terms of effective crisis communication strategy at the global level? By reviewing Wuhan's overall communications structure as a dynamic complex system through a panoramic perspective, this paper explores risk and crisis communication from the early stages of the "novel pneumonia" to the overall stabilization of the crisis.

Risk communication and crisis communication are intertwined - any risk that is explained ineffectively can become a crisis. ${ }^{5,6}$ In order to approach health risk and crisis communication strategically, this paper considers the breadth of specialisms within effective communication, including public relations, public affairs, marketing, and social media. ${ }^{6}$ Timely and effective risk communication enables effective disaster governance, a better adaptive response to crisis communication, and leads to a higher reputation for government organizations. ${ }^{7}$

Public risk perception is influenced by both the hazard and outrage. ${ }^{8}$ According to Malecki et al, COVID-19 has eight factors that affect "outrage" (the public's emotional reaction): catastrophic potential, unfamiliarity, lack of clarity, scientific uncertainty, lack of personal control, varying levels of voluntary behavior (eg around mask wearing), varying trust in institutions and varying levels of media attention. ${ }^{9}$ This study answers Malecki et al's ${ }^{9}$ call for more COVID-19 studies of risk communication, and updates Zhang et al's time-limited study of Wuhan's risk communication up until January $18,2020 .^{10}$

\section{Materials and Methods}

We use complex adaptive systems theory (CAS) to theorize the communication strategy that was led by the Hubei Province COVID-19 Epidemic Prevention and Control Headquarters. The thinking in this paper derives from our theoretical perspective on the application of CAS for disasters, ${ }^{11}$ which was influenced by the five CAS concepts proposed by Coetzee et $\mathrm{al}^{12}: 1$ ) non-linearity: the inputs into the system may not result in proportionate expected outputs; 2) aggregation: new groups are formed during disasters; 3) emergent behavior: subjects show new behaviors; 4) feedback loops and adaptation: different parts of the system evolve from one another, and 5) context-based responses, where the importance of context is essential to the functioning of each unique system. CAS theory allows the identification of complex patterns and interrelationships between agents. The benefit of CAS is that it does not theorize complexity in relation to "cause and effect", but instead prioritizes the high-level analysis of inter-agent relationships, and emerging and iterative patterns. Holland theorizes CAS as a dynamic network of agents acting in parallel, constantly reacting to other agent's actions, which influences behavior and the wider network. ${ }^{13}$ CAS prioritizes the understanding of phenomena as a holistic system, and we present a review of Wuhan's communication system in the unique panorama of the location of the COVID-19 outbreak. As we will argue, a CAS model is beneficial for theorizing how to build resilient leadership in government risk and crisis communication, enhance communication effectiveness, enhance the authority and credibility of government, and promote adaptation and learning within the general public. With the rapid spread of COVID-19 across the world, the consideration of effective communication strategies from Wuhan can provide valuable insight to other countries in how to manage their risk response.

Ethnographic fieldwork was used to investigate the dynamic processes of the disaster's development and communication. The first author's hometown is located in the Hubei province, which allowed close ethnographic observation to be undertaken. She observed the risk and crisis communication in Wuhan from December 31, 2019 to April 30, 2020, and collected materials, including the offline interaction of different subjects, government policy texts, government press conferences, publicly available new media communication texts, and made a consideration of online and offline public sentiment. The data collection methods include high-level participatory and non-participatory observation, and document collection and analysis to observe both the government level and civil level. Throughout the observation period, the first author was active on social media (WeChat and Weibo) monitoring real-time information releases, and interacting with relatives and friends during the period of Wuhan city closure to understand the background context. Triangulation and 
corroboration were carried out on the data gathered from different sources in order to achieve a holistic picture. As Gamburd emphasized, ${ }^{14}$ disaster scenes can present complex challenges to researchers as the practice of disaster response is a dynamic process of intense multi-level social action. Reflexivity was employed by the first author, in discussion with the other authors, to reflect on her intimate knowledge of her hometown, ethics, the sudden worldwide attention on Wuhan, "public" and "private" interactions, and her implicit and explicit subjective knowledge about Wuhan in relation to the theorization of the CAS.

Discourse analysis was used to analyze the text data obtained during the fieldwork, using a method influenced by Van Dijk. ${ }^{15}$ Van Dijk's method has been frequently used in communication studies because it theorizes news as a complex communicative event (discourse). ${ }^{16}$ Van Dijk's method was selected because it allows understanding of the complexity between text and the background context, ${ }^{15}$ something crucial to the context-specific nature of the complex adaptive system in Wuhan. In this paper, we formulate an overview of all communications platforms used in Wuhan, analyzing internet forums and press conferences. Communications tools are influenced by cultural norms that influenced the data selection. Press conferences are an important communications element to analyze because press communication is normalized and institutionalized in China as a way to give the public health information, curb rumors, calm panic and boost public confidence in the government. ${ }^{17}$ We also review internet forums because Cao et al state that seeking digital information online was a crucial aspect of the Chinese public's response to SARS, ${ }^{18}$ while Tai and Sun argue that Chinese citizens used the internet to resolve ambiguity in response to the Chinese government's tight information control. $^{19}$

\section{Results}

\section{System Objectives}

This article reviews the communication approach from the start of the lockdown period (January 23, 2020). The Wuhan government's actions were affected by the number of COVID-19 cases present (see Figure 1), which we categorize through four distinct stages.

- Stage 1: Early warning: December 31, 2020 (Wuhan Municipal Health Commission first officially reported "pneumonia" cases) until January 22, 2020. After the first COVID-19 patient was reported, the existing COVID-19 active cases in Wuhan rose from 1 case to 399 cases.

- Stage 2: Crisis escalation: January 23, 2020 (Wuhan lockdown) until February 4, 2020. The number of existing COVID-19 cases in Wuhan rose sharply from 399 cases to 7618 cases, an increase of 7219 cases in just 12 days (an average increase of 601.58 cases per day).

- Stage 3: Effective control: February 5, 2020 (first batch of "Fangcang shelter" hospitals, which are large-scale and temporary, are established) until March 10, 2020 (all Fangcang shelter hospitals are "vacant"). ${ }^{20}$ The existing COVID-19 cases increased from 7618 cases on to 38,020 cases on February 18, 2020. Cases then gradually decreased to 14,514 cases

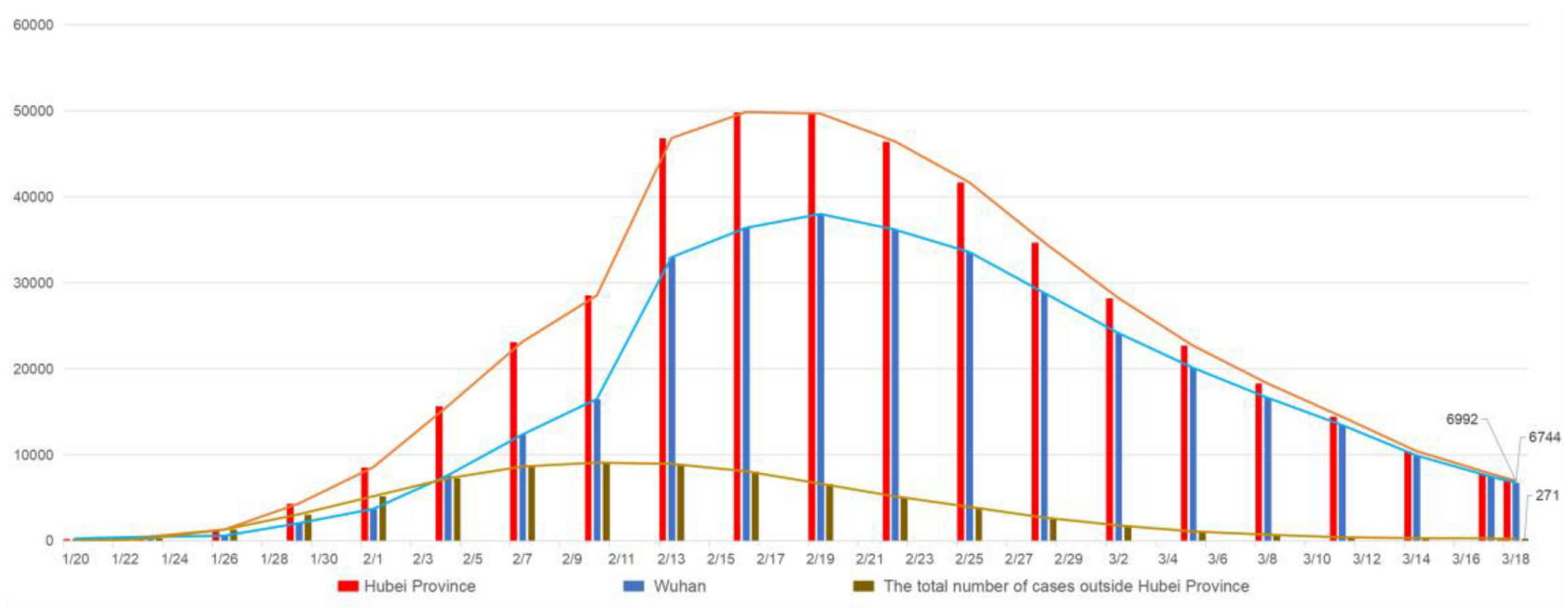

Figure I The number of COVID-19 cases in Wuhan. 
on March 10, 2020 - a total decrease of 23,506 cases and an average decrease of 1068.45 cases per day.

- Stage 4: Handling and consolidation: March 11, 2020 - present. After March 11, 2020, the existing COVID-19 cases in Wuhan further decreased from 13,462 cases to 6744 cases on March 18, 2020, with an average decrease of 959.71 cases per day. The Wuhan government is continuously working to detect new cases.

The stages of the Wuhan crisis then determined the communication responses, which are discussed throughout this paper. The risk and crisis communication approach adopted by the government to manage COVID-19 is shown through Table 1 (emergency commitments made by the government) and Table 2 (risk and communications approaches). The system objectives and their relation to the whole system are in Figure 2. As Table 2 and Figure 2 show, effective health communication in Wuhan necessitated an approach that centered public needs, including a recognition that health needs were contingent on other aspects of government strategy like the financial markets and employment. Health policies and structural factors had a crucial influence upon patient treatment outcomes, particularly mental health, during the COVID-19 pandemic.

\section{Meet Emergency Commitments}

An emergency commitment refers to the government giving early assurance that if certain perceived risks occur in the future, the government will make corresponding remedial measures to alleviate public anxiety about the risks. ${ }^{31}$ Making an emergency commitment can help to improve and maintain the relationship between the government and the public (subjects), and consolidate and enhance the reputation and credibility of the government by providing reassurance in uncertain situations. ${ }^{31}$ As Wuhan was the first case of COVID-19 reported internationally, the government's reassurance about the public's health was even more crucial. In major crises, in addition to appeasing groups that may be damaged by risks, making an emergency commitment can also help the subjects to establish clear prevention and control objectives and build consensus on common actions. Therefore, making emergency commitments is the key way to build an adaptive crisis communication system.

In Stage 2 (Crisis escalation), the central Chinese government communicated to "fully check all suspected cases; treat and cure all the infected", ${ }^{23}$ which was used to drive all subsequent communication and operational decisions. The government had little knowledge about the degree of risk from the novel coronavirus - they had to rely on a reserve of emergency materials, organize large-scale

Table I Emergency commitments made by the government

\begin{tabular}{|c|c|c|}
\hline $\begin{array}{l}\text { Stage that the policy was } \\
\text { first announced }\end{array}$ & Type & Examples of key logistical policies used to reassure the public \\
\hline Stage 2 & $\begin{array}{l}\text { Food and } \\
\text { supplies }\end{array}$ & - Development of a shopping platform for residents. ${ }^{21}$ \\
\hline Stage 2 & $\begin{array}{l}\text { PPE/ } \\
\text { Health }\end{array}$ & $\begin{array}{l}\text { - Government promises to 'fully check all suspected cases; treat and cure all the infected' } \\
\text { - As of } 30 \text { January, the Wuhan government received a total of } 6.543 \text { million tons of donated } \\
\text { materials from the Hubei Provincial Red Cross, Provincial Charity Federation, and Provincial Youth } \\
\text { Development Foundation. They also received } 26,600 \text { sets of medical protective clothing, } 479,000 \\
\text { N95 masks, I.7287 million disposable medical masks and 39,300 goggles. }{ }^{22}\end{array}$ \\
\hline Stage 2 & $\begin{array}{l}\text { Health } \\
\text { costs }\end{array}$ & - The National Ministry of Finance promised free medical treatment for all COVID-19 patients. ${ }^{23}$ \\
\hline Stage 2 & Jobs & $\begin{array}{l}\text { - From January } 2020 \text {, Wuhan increased unemployment insurance benefits to } 90 \% \text { of the minimum } \\
\text { wage. }^{24}\end{array}$ \\
\hline Stage 3 & Jobs & $\begin{array}{l}\text { - The government pledged to increase social insurance support, reduce taxes, fees and rents for } \\
\text { enterprises, and further strengthen financial support for the development of SMEs. }{ }^{25,26} \\
\text { - The price subsidy was doubled for college graduates, migrant workers, and people who were } \\
\text { having trouble finding jobs.' }\end{array}$ \\
\hline
\end{tabular}




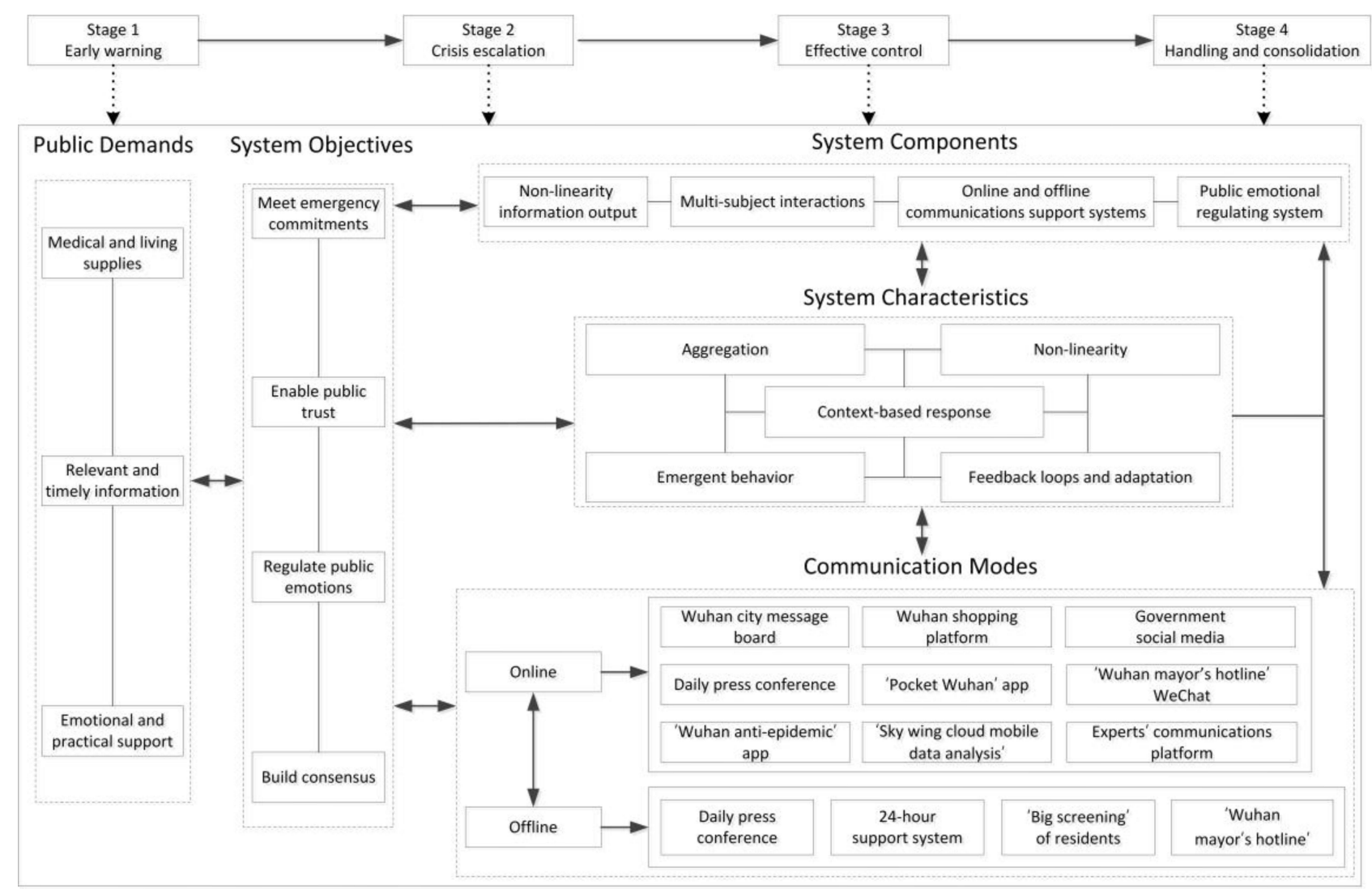

Figure 2 Adaptive risk and crisis communication system.

human resources support and develop flexible policies. Table 1 shows some examples of emergency commitments made by the government to boost morale in the public ahead of projected and present issues, which were developed through public outreach and feedback mechanisms.

\section{Enable Public Trust}

Public trust 'enables cooperative behavior, promotes adaptive organizational forms ... reduces harmful conflict, and promotes effective responses to crisis' ${ }^{32}$ Ensuring public trust is the cornerstone of the government's risk management approach, and is an indispensable foundation for the effective application of the system functions of risk and crisis communication. The construction (and recovery) of trust through communication determines the government's credibility, supporting its implementation of various risk management policies to the satisfaction level of the public.

In Stage 1 (Early Warning), compounded by the difficulties in understanding the complex nature of the novel coronavirus, the government was slow to make adequate emergency preparations, communicate information and take action. In this communication vacuum, negative rumors spread both in China and internationally, including speculation that the virus was deliberately leaked from a scientific lab in Wuhan, which was later contradicted by the Wuhan Institute of Virology. In the early stages of the crisis response, while a "man-made" origin has since been refuted, ${ }^{33}$ questions about whether COVID-19 was deliberately manufactured made the COVID-19 pandemic different to other pandemics like influenza. At this early stage, the government's credibility was damaged, and they needed to work to restore public trust.

As this article will show, the Wuhan government actively made adjustments to their strategic communications in Stages 2-4, focusing on the recovery of trust through engagement with local people and journalists. They also developed operational mechanisms to manage suspected cases, developed new communication platforms and encouraged the participation of a diverse range of stakeholders.

\section{Regulate Public Emotions}

In Stage 1 (Early Warning), due to the information asymmetry between the government and the public, it was 
difficult for the public to obtain sufficient and effective risk information, thus hindering the formation of reasonable risk perception. Risk perception refers to people's subjective estimation of the possibility that negative health-related outcomes or incidents can occur. ${ }^{8}$ If risk perception is too low it can lead to negative psychological coping strategies and safety negligence, but if the risk perception level is too high it can easily lead to public panic, resulting in a series of secondary disasters, such as violent conflicts, damage to the credibility of the government, and more serious social losses. ${ }^{8}$ As Wuhan shows, the public's risk perception led to a spate of panic buying of food and supplies which then led to widespread concern on social media, causing a food supply crisis which then had to be mitigated by the government. When building its risk and crisis communication system, the Wuhan government made prioritizing public mental health and emotional counseling its core objectives. It developed a series of communication mechanisms to a) ascertain people's emotional state by issuing online questionnaires; b) analyze and monitor any changed trends in overall social mood; and c) use an interactive communication platform so that the public could talk to professional psychologists.

\section{Build Consensus}

Risk and disaster governance is a complex phenomenon that requires the participation of all stakeholders (subjects). When consensus is reached by the subjects on the purpose and nature of risk and crisis communication, it can clarify goals and direction for cooperation, reduce communication conflicts, improve the efficiency of the governance measures, and achieve desirable risk governance results.

After losing some trust in Stage 1 (Early Warning), during the period of lockdown in Stage 2, the Wuhan government worked to build consensus. As shown later in Table 2, the government both developed new interaction platforms, and utilized existing platforms, as part of its aim to create opportunities for the government, enterprises, social organizations and citizens to participate in two-way communication.

\section{Building an Adaptive Risk and Crisis Communication System}

At the start of lockdown in Stage 2, the municipal government suddenly had to respond to four main needs from the 11 million residents: 1) provide real-time information, 2) reassure and reduce stress, 3) provide medical and living supplies and 4) provide feedback on practical issues. In a complex and fluid dynamic that necessitated integrated risk and crisis communications, the government employed crisis communications to deal with the issues, and risk communications to stop further issues developing. The communication objectives were to communicate three specific elements: 1) respond to rumors/communicate health information; 2) promptly announce government measures; 3) make emergency commitments to reassure the public. This necessitated a shift in communication strategy, and the development of 6 new communication modes specifically for the COVID-19 health crisis (see Table 2). In response to SARS in 2003 and A/H1N1 in 2009, the Chinese government had evolved their health communication and insisted on multi-departmental cooperation across government departments, experts, media and grassroots organizations, ${ }^{34}$ a strategy that has also been employed by the Wuhan government for COVID-19. The adaptive crisis communication system that was constructed is a typical complex adaptive system with five characteristics: nonlinearity, aggregation, emergent behavior, feedback loops and adaptation, and a context-based response.

\section{Non-Linear Information Output}

The inputs into a complex adaptive (CAS) system can have unexpected results, and the system is not static (see Figure 2). In order to cope with the ever-changing environment, the evolution of Wuhan's risk and crisis communication system is achieved through the continual adjustment of communication strategies in relation to the frequent interaction of diverse stakeholders (subjects). Non-linear information output refers to the government's flexible adjustment of its offline and online communication methods in response to both the development of the crisis and from public feedback.

Discourse analysis was made of the data from the first 15 press conferences on the "Prevention and Control of COVID-19" held by the Hubei provincial government from January 22, to February 5, 2020. ${ }^{24}$ Spokespeople were first used for health communication by the Chinese government during the SARS outbreak ${ }^{35}$ and should communicate with concern, clarity, control, confidence and competence. ${ }^{36}$ Through the analysis of this time period as the crisis evolves from Stage 1 to Stage 2, a clear shift in health crisis communication strategy is shown in three ways.

Firstly, in the early stage of the lockdown, the speakers at the press conference were mainly government officials. 


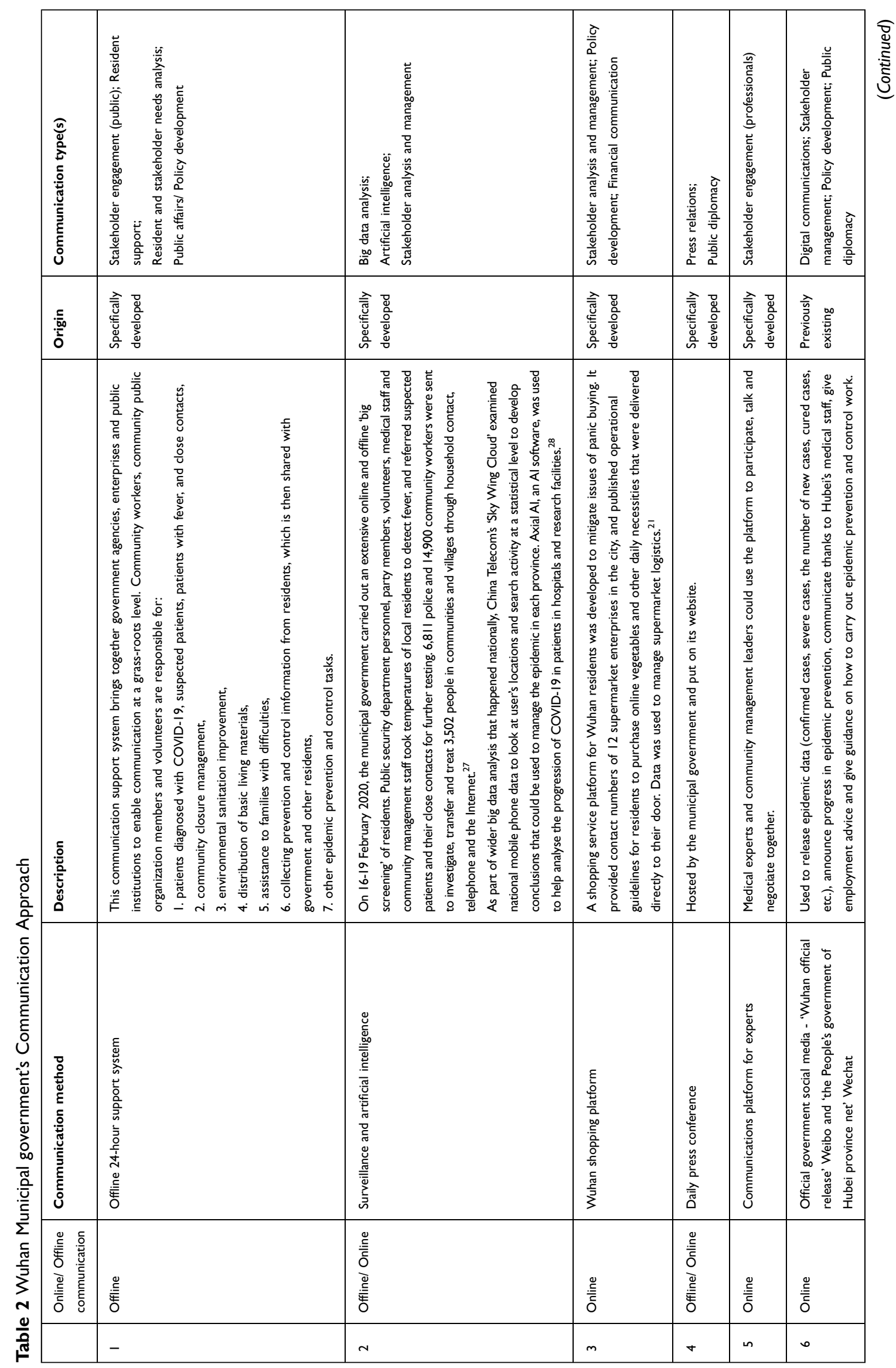




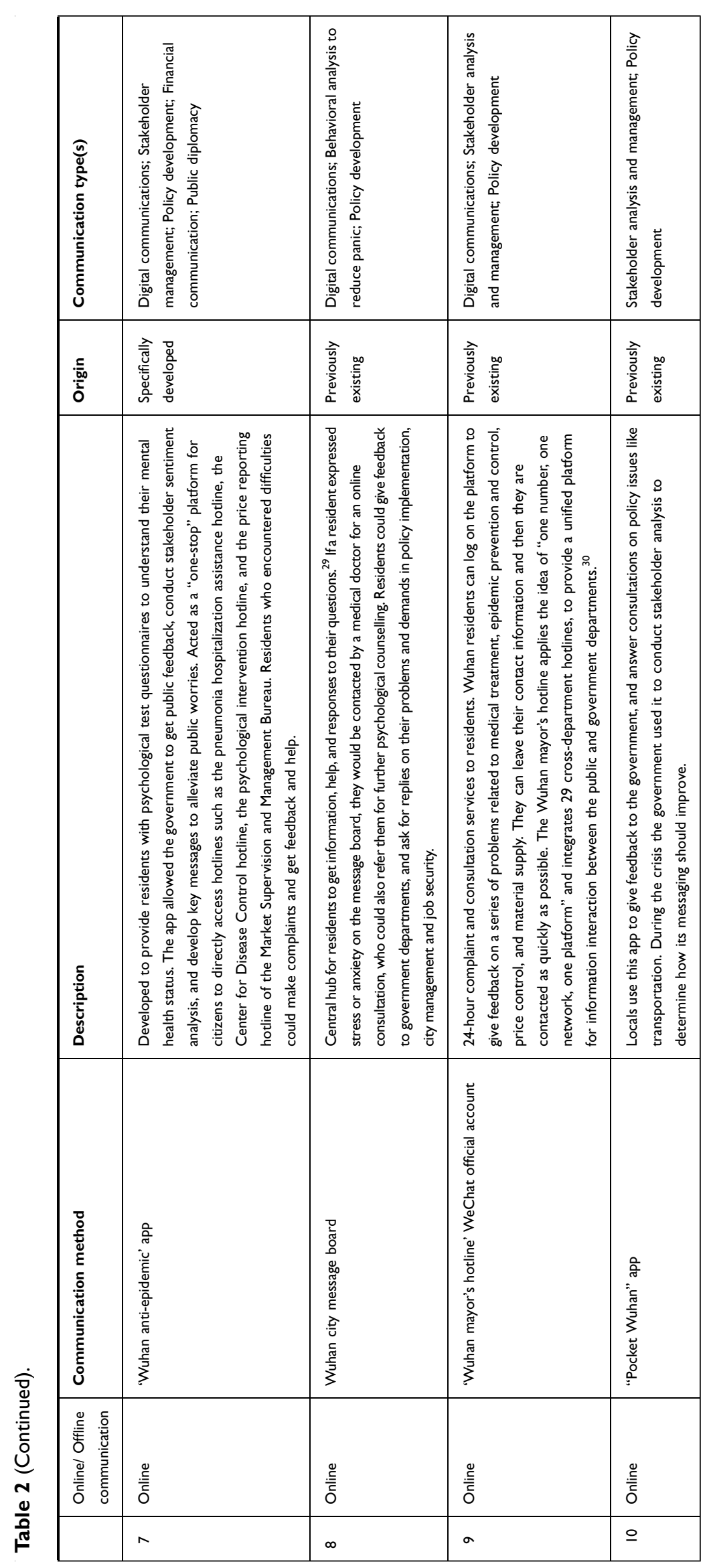


The government conducted analysis of public feedback to determine that the public would be more reassured by press statements from medical and public health experts (competence) as these were viewed as more authoritative and knowledgeable (control, clarity) in advising the public on appropriate risk prevention and control measures. After the first 8 days of conferences, the government then adjusted its press conference approach (concern) to have one medical professional featuring in every daily press conference.

Secondly, COVID-19 is a new risk with little clarity about the coronavirus or its health implications. With new risks the public tend to feel greater fear and anxiety compared to more familiar risks, thus creating a greater demand for clear information and communication from the government. Leng et al's sentiment analysis of posts on Chinese social media (Weibo) found that there was a rise in fear between Jan 29, 2020 and Mar 18, 2020. ${ }^{37}$ In addition, COVID-19 is an invisible risk, that cannot be visually seen like the physical damage caused by earthquakes, typhoons and other natural disasters, causing gaps in people's risk perception. Consequently, the public is demanding more from governments that respond to their own appeals and delivers on its promises (clarity, confidence). Across the 15 press conferences, 116 questions were asked in total, and 109 questions were answered (94\%). 6\% of questions were not answered because the answer was not yet known. In order to better respond to peoples' demands, the government allowed more questions from the public - increasing from 41 questions in the first eight conferences, to 75 questions in the subsequent seven conferences.

Finally, the government adapted its messaging from describing the epidemic as "preventable and controllable" to a more empathetic approach (concern) that instead recognized the "uncertainty" that local people were experiencing (such as acknowledging that the total number of infected persons had not yet been determined). Analysis of the communication of "uncertain" information that was released in press conferences showed discussion of uncertainty rose dramatically: it was only discussed 2 times in the first eight press conferences, but 11 times in the subsequent seven press conferences.

\section{Aggregation: Multi-Subject Interactions}

In complex systems, individuals self-organize into their own groups. In Wuhan's adaptive crisis communication system, all communication subjects interacted in the process of epidemic prevention and control, and jointly reached a set of unified epidemic prevention and control objectives. Mutual adaptation of behavior modes among subjects promoted the optimization of system structure and effective function. Communication is an important way for multiple social subjects to participate in risk management it is of great importance that strategic communications facilitates the interaction of diverse stakeholders on resource integration and information aggregation, to enhance the efficiency of the emergency response. As well as adapting its press conference strategy to include more specialists, the Wuhan municipal government also provided a communication platform for medical experts and community management leaders to talk and negotiate together. At the same time, the government also carried out large-scale cooperation with private enterprises, such as the cooperation with Sina Weibo and WeChat, to ensure that communication could be rapidly promoted on social media.

\section{Emergent behavior: Online and Offline Communications Support Systems}

Emergent behavior describes how subjects can personally decrease the likelihood of exposure to an infectious disease or assist in treatment through their actions. ${ }^{38}$ During this epidemic, the subjects in the Wuhan adaptive communication system interacted with each other and adapted to the development of the epidemic continuously. Each subject had a different disaster response that formed a diversified response mode in the process of continuous interaction, which led to the dynamic diversity of the whole crisis system.

The city lockdown meant a radical shift to the lifestyle of residents and a risk of increasing psychological stress and anxiety - the health communication strategy must mitigate these issues. In contrast to Song, Zhang and Dolan, ${ }^{11}$ unlike in other crises when an average member of the public can show emergent behavior in new coping strategies, the challenge of this crisis was that the public were isolating at home, reducing their feelings of autonomy and control. This puts more responsibility on the role of health communicators to support their mental health and wellbeing.

Given the scale of the crisis, one-way communication through the media is not sufficient. Table 2 shows how the Municipal government built an offline communications support system to help support residents. This approach was particularly effective in reaching vulnerable groups that are less confident online (helping breach the "digital divide"), but also understanding their needs and providing tailored assistance. As of March 10, 2020 (the end of 
Stage 3), more than 10,000 government agencies, enterprises and public institutions in the Hubei province had contacted 27,345 communities (villages), and organized more than 580,000 party officials to join the epidemic prevention and control work at grass-roots level. ${ }^{39}$ These groups were instrumental in explaining to the residents the latest epidemic prevention policies and community management regulations to help the residents understand and comply.

\section{Context-Based Communication}

The establishment of a "top-down" communication system quickly enhanced the interaction between the various stakeholders, enhanced by the rapid injection of more resources into the (identified) weakest links of epidemic prevention and control. In part, this success is due to the context-based response that was tied into Chinese culture, where top-down communication is common in China and is expected by the Chinese public. ${ }^{40}$ Sender-focused (topdown) communication can aid the public to plan ahead, through communicating responsibly to minimize harm. ${ }^{41}$ However, these sender-focused practices are based on an inherent assumption that receivers will respond appropriately during a crisis when presented with (a) an honest explanation of what is occurring and why, as well as (b) how the organization is responding effectively to it. ${ }^{42}$ Sellnow argues that effective instructional communication is not measured by information shared by the sender (eg, the instructor), but rather, by affective (ie, perceived value and utility), cognitive (ie, knowledge comprehension) and behavioral (ie, action/performance) learning outcome achievement among receivers. ${ }^{41}$ Hence, effective instructional crisis communication must include elements not only of information explanation, but also of internalization (proximity, timeliness, personal impact) that motivate receivers to realize the value/utility of the message content and action (specific behavioral directions) that specify exactly what receivers are to do for self-protection. This is even more important for communication about healthrelated issues, where the seriousness and specialist knowledge required mean that governments across the world can often use top-down communication for health issues, particularly in the early stages of a crisis. ${ }^{43}$ We argue that the Wuhan government primarily took a top-down risk and crisis communications strategy in order to build trust in a context-specific way, and communicate clearly about a complex and uncertain health issue. This top-down approach was tailored specifically to the Chinese culture and may not be suitable for other cultures or countries. Combined with this top-down approach, the government also incorporated feedback from the receiver (bottom-up) by developing mechanisms for the public to feed back on the government's response (see Table 2). The top-down and bottom-up approach was based on the government's context-specific knowledge of Chinese culture and Wuhan citizen's needs, which were viewed as dynamic.

Social media platforms have impacted health communications because the public expect to give governments their views for improvement. ${ }^{43}$ The communication systems (the "Wuhan mayor's Hotline" WeChat, the Wuhan City Message Board and the "Pocket Wuhan" App) also enabled more effective crisis communication by facilitating "bottom-up" feedback from residents, which was analyzed and then used at all levels of government to refine communication and strategy. For example, in the early part of Stage 2 , the residents communicated difficulties in purchasing maternal and infant supplies, and challenges in rural logistics and distribution, which the government, supermarket enterprises and communities worked to resolve.

Through the integration of online and offline communication and feedback channels, the Wuhan government has ensured that people of different ages, different levels, different fields and different levels of knowledge had equal opportunities to find about risk information, and satisfy the public's needs for real-time feedback on issues and demands. This is a shift since the SARS outbreak in 2003, where the Chinese local government's health communication was criticized for deliberate concealment of official data, ${ }^{44}$ and where their mistakes damaged public trust. $^{45}$

\section{Feedback Loops and Adaptation: Public Emotional Regulating System}

When a crisis occurs, anxiety and stress can quickly spread and evolve, sometimes triggering a series of secondary issues in a chain effect. This can be compounded by fake information, which has become an increasing concern for communicators in handling their disaster response. Therefore, rapid feedback and mediation to the public's stress has become a key way to avoid secondary issues like violence and conflict, and to mitigate a lack of trust in government. Our research showed that the three main causes of anxiety that were expressed by Wuhan residents were questions about the symptoms of COVID-19, stress and concerns about the shortage of medical supplies such 
as masks. As Table 2 shows, the Wuhan government developed the "Wuhan Anti-epidemic" app and used the Wuhan City Message Board to communicate with and listen to residents. From January, 23 to April, 152020 there were 240 messages about "anxiety" in the Wuhan City Message Board, accounting for $55.7 \%$ of the (431) total messages about "anxiety" since the platform opened in $2017.100 \%$ of these messages received comments and suggestions from medical experts. ${ }^{29} \mathrm{Du}$ et al found that communications messaging was not meeting the real needs of the public. ${ }^{44}$

Furthermore, during the outbreak of the epidemic, the number of calls received per day for the mayor's hotline was 16,000 calls, reaching 24,000 calls at the peak, which was 2-5 times the normal amount. ${ }^{46}$ The number of complaints from patients who had difficulty getting treatment peaked at 1637 on February, 82020. After the development of the operational and communication mechanisms discussed in Table 2, the complaints declined continuously after February 11, 2020 with a drop of nearly $90 \%$ from the peak. ${ }^{46}$ According to the tracking of the cumulative number of confirmed COVID-19 cases in Wuhan (see Figure 3), the cumulative number of confirmed COVID-19 cases in Wuhan increased gradually from 375 on January, 21 to 50,007 on March, 31. The cumulative number of confirmed cases in Wuhan increased rapidly from February, 1 to February, 20, and 13,436 cases of COVID-19 were diagnosed in one day on February, 12. Since then, from the end of February to the end of March, the growth rate of confirmed COVID-19 cases in Wuhan has leveled off, but there are still new cases every day. Therefore, the decrease of complaints in Wuhan mayor's hotline is not directly related to a decrease in the number of confirmed cases in Wuhan overall. It suggests that the Wuhan mayor's hotline, combined with other communications types (see Table 1), played an important role in allowing the public to express their demands, in solving problems encountered by the public and in calming public emotions.

\section{Conclusion}

COVID-19 is a public crisis of complexity and uncertainty - as a widespread and "invisible" emergency, it is causing great damage and considerable difficulty in prevention and control. Disease does not ascribe to geographical boundaries - our theoretical contribution is a CAS model to facilitate global comparison through an explicit focus on Wuhan. There are key communications differences between Western and Eastern (Chinese) cultures, and risk and crisis communications should be culturally specific. When responding to COVID-19, the complex

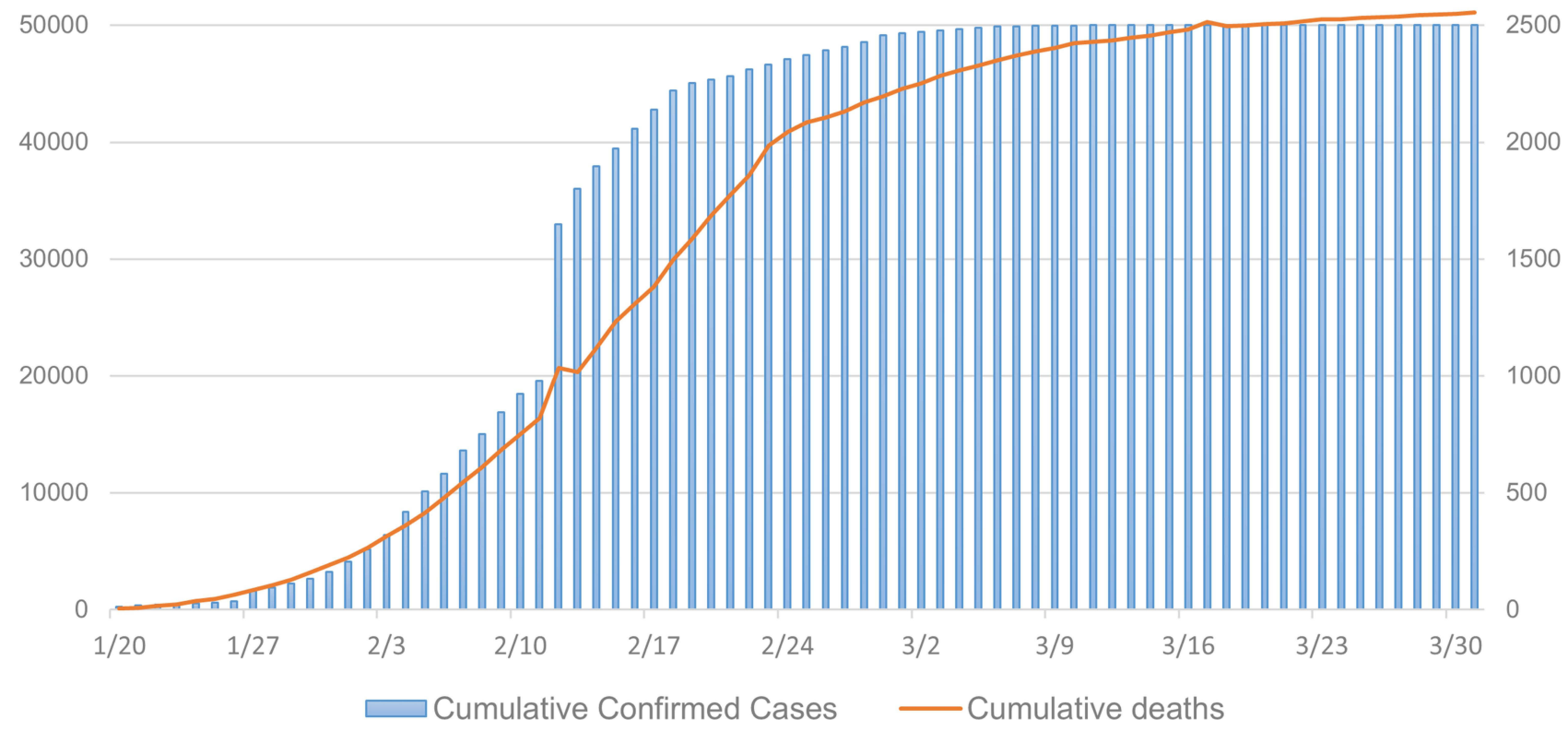

Figure 3 Wuhan's cumulative confirmed cases and cumulative deaths. 
interaction between policies, cultural differences and behavior are very different across the world. ${ }^{47}$ Theorization of the Wuhan communications system as a typical CAS enables country comparison through five characteristics: nonlinearity, aggregation, emergent behavior, feedback loops and adaptation, and contextbased response. In similarity to our previous findings in Song, Zhang and Dolan (2020), ${ }^{11}$ the context-based responses by the government and citizens produced corresponding complex adaptive behavior, which constantly evolved the communications system in a non-linear and dynamic way. The Wuhan public (subjects), while limited in physical movement due to lockdown, were still able to communicate with the government through online and offline methods.

There are three key findings of this study. Firstly, Wuhan's adaptive risk and crisis communication system was backed by digital and offline infrastructure, human resources support, policy development, as well as access to scientific and technological expertise. Secondly, the predominant communication mode was top-down communication (tailored specifically to Chinese culture), but the roles of public feedback and two-way communication are emphasized in policies to support the integration of government, enterprises, social organizations and the public. Thirdly, these communication tools support government aims to meet emergency commitments, recover trust, regulate the public's emotions and build consensus. As we theorized through the CAS, the Wuhan government quickly constructed its communication system through five main components: (1) non-linear information output, (2) online and offline continuous support systems, (3) a public emotional support system, (4) multi-subject information interaction platforms and (5) a context-based approach.

Our conclusions are similar to other research. For example, through online questionnaires, Chao et al's research found that new media use during the outbreak was associated with negative psychological outcomes like depression. ${ }^{48}$ They found that official social media accounts, with timely and clear information from authorities and medical experts, may offset the latent negative impact caused by other forms of media sharing. ${ }^{48}$ Chen et al's study of the Sina Weibo official account of the National Health Commission of China drew a similar conclusion to our study: matching crisis-related information demand and information supply determines the effect of online communication. ${ }^{49}$ Positive information like praising frontline health care workers, and clear news about the development of the epidemic and the government's handling of the crisis can enhance the interactive engagement of the public. ${ }^{49} \mathrm{Li}$ et al's findings indicated that, unlike the relationship between the government and social media in other countries, the Chinese government worked to directly communicate through the large social media platform-Sina Weibo. ${ }^{50}$ This not only speeds up the relief effort, but also makes it easier to motivate citizens and nonprofit organizations to support the government response and recovery efforts. ${ }^{50}$ This conclusion is consistent with the view of multi-agent participation in the adaptive communication system that was proposed in our study.

However, our study also diverges from some existing research on some important points. We update the thinking of Zhang et al who studied Wuhan's risk communication up until January $18,2020 .{ }^{10}$ They saw Wuhan's risk communication as ineffective, but we show how the government later adapted their risk communication, included scientific expertise, and tried to rebuild public trust. Liao et al captured data related to COVID-19 from December 1, 2019 to January 31, 2020, and extracted information related to public engagement from posts issued by official government accounts, such as likes, comments, shares and followers, so as to measure the level of online interaction between the public and the government. ${ }^{51}$ Liao et al argued that the government mainly adopts a top-down risk communication approach and uses social media as a one-way communication method ${ }^{51}$ - this top-down approach was certainly used in the very early stages of the crisis. However, we also found that the Wuhan government later carried out a lot of offline community crisis communication, and also used bottom-up communication on social media to collect public demand information and feedback. The government's risk and crisis communication is two-way, combining top-down and bottom-up, to construct a feedback loop and adaptation system. Other studies back up our findings: Chen analyzed government announcements, posts and articles, as well as national and international news releases to mid-January, to argue that Chinese social media is not just a place for selfcensorship and surveillance by the government. ${ }^{52}$ On the contrary, during the outbreak of COVID-19, social media became a space for active public engagement, where Chinese citizens expressed concern and solidarity, participated in claim-making and resistance, and negotiated with official authorities. ${ }^{52}$ 
We have advocated an original contribution of considering risk and crisis communication through complex adaptive system theory. A key benefit of this approach was to highlight that the uncertainties within the system like the medical impact of the virus or suitable actions to take - were all unclear, and necessitate complex risk and crisis communications methods. There are three main limitations to this study. Firstly, in emphasizing the complexity and fluidity of the system, the approach does not consider the micro-level detail - a task we leave to other scholars. Secondly, this study has prioritized the analysis of social media and press written texts. However, nonverbal communication is an essential aspect of communications practice - it is necessary to develop techniques and methods to deal with non-verbal symbolic information. Thirdly, we have previously theorized several variable factors that affect self-organizing mechanisms - culture, language, identity, time, knowledge/skills and trust. ${ }^{11}$ While CAS helps us theorize the "unknown", a key challenge of applying CAS theory to COVID-19 communications is that the behavior of people within the system is not predictable $^{12}$ - other academic studies must prioritize psychological approaches to help understand self-organizing and variability in human behavior in relation to these variable factors.

As a key strategic player in risk response, emergency communication practitioners and scholars must position themselves at the forefront of the pandemic responses. Future communication research should consider three areas:

1. Explore the international framework of the complex adaptive system. How has the communication strategy for COVID-19 evolved as the crisis escalated from an epidemic to a pandemic? What does the complexity of the adaptive system look like as it evolved from the regional to the national to the international? Some scholars have studied the responses of countries such as Finland, ${ }^{53}$ the United States ${ }^{54}$ and Vietnam, ${ }^{55}$ but there is still a lack of research from a systematic perspective.

2. Review communication responses at country-level. China is a collectivist society, which is more focused upon maintaining social cohesion than individual interests. Residents mostly complied with the lockdown rules, which has not been the case in other countries like the United States. What context-specific communications strategies did other countries use to manage the lockdown and/or pandemic communication?

3. Analyze communication specialisms. This article has focused upon the external health communication at Wuhan, but further research should examine other specialisms like employee (internal) communication, financial communication and international public diplomacy. The use of big data, surveillance and artificial intelligence to tackle COVID-19 in other countries should be further examined from a health communication perspective.

\section{Acknowledgments}

We are very grateful to Bernard Carey, Fellow of the Chartered Institute of Public Relations, for his insightful comments on this paper. As a low-risk project, this research was exempt from ethics approval because we did not conduct interviews, surveys or experiments with the public. We thank the Editor and our anonymous Reviewers for their detailed and supportive feedback. Funding for this work was provided by the Chinese National Social Science Foundation (Grant No. 16CGL061), and the Economic and Social Research Council (ESRC), United Kingdom.

\section{Disclosure}

The authors report no conflicts of interest in this work.

\section{References}

1. Government. [Homepage on the Internet], Press Conference [In Chinese]; 2020. Available from: http://www.hubei.gov.cn/hbfb/ xwfbh/. Accessed May 28, 2020.

2. Tian H, Liu Y, Li Y, et al. An investigation of transmission control measures during the first 50 days of the COVID-19 epidemic in China. Science. 2020;368(6491):638-642.

3. BBC News. Sierra Leone declares Ebola lockdown. Available from: https://www.bbc.com/news/world-africa-29093048. Accessed April $28,2020$.

4. Tian D. More than 3500 "four categories of personnel" were screened out in Wuhan "network pulling" [In Chinese]. Beijing News. Available from: http://www.bjnews.com.cn/feature/2020/02/23/693778.html. Accessed April 27, 2020.

5. O’Hair D. Measuring Risk/Crisis Communication: Taking Strategic Assessment and Program Evaluation to the Next Level. Risk and Crisis Communication: Building Trust and Explaining Complexities When Emergencies Arise. Washington, DC: Consortium of Social Science Associations; 2004:5-10.

6. Reynolds B, Seeger MW. Crisis and emergency risk communication as an integrative model. J Health Commun. 2005;10:43-55.

7. Glik DC. Risk communication for public health emergencies. Annu Rev Public Health. 2007;28:33-54.

8. Slovic P. Perception of risk. Science. 1987;236(4799):280-285. 
9. Malecki K, Keating JA, Safdar N. Crisis communication and public perception of COVID-19 risk in the era of social media. Clin Infect Dis. 2021;72:697-702.

10. Zhang L, Li H, Chen K. Effective Risk Communication for Public Health. Emergency: reflection on the COVID-19 (2019-nCoV) Outbreak in Wuhan, China. Healthcare. 2020;8(1):64.

11. Song Z, Zhang H, Dolan C. Promoting disaster resilience: operation mechanisms and self-organizing processes of crowdsourcing. Sustainability. 2020;12:5.

12. Coetzee C, Van Niekerk D, Raju E. Disaster resilience and complex adaptive systems theory: finding common grounds for risk reduction. Disaster Prev Manag. 2016;25:196-211.

13. Holland JH. Adaptation in Natural and Artificial Systems: An Introductory Analysis with Applications to Biology, Control, and Artificial Intelligence. Cambridge, Mass: MIT Press; 1992.

14. Gamburd MR. The Golden Wave: Culture and Politics After Sri Lanka's Tsunami Disaster. Bloomington: Indiana University-Press; 2014.

15. van Dijk TA. News as Discourse. New York: Lawrence Erlbaum Associates; 1988.

16. Fairclough N. Critical Discourse Analysis: The Critical Study of Language. London: Routledge; 2010.

17. Zhao YY, Ren ZM. The gain, loss and role of newspaper media in risk communication: an example from the report of influenza A/H1N1 epidemic in Lanzhou Morning Post. Journalism Lover. 2010; 5: 32-33.

18. Cao W, Zhang X, Xu K, Wang Y. Modeling online health information-seeking behavior in China: the roles of source characteristics, reward assessment, and internet self-efficacy. Health Commun. 2016;31(9):1105-1114.

19. Tai Z, Sun T. Media dependencies in a changing media environment: the case of the 2003 SARS epidemic in China. New Media Soc. 2007;9:987-1009.

20. Chen S, Zhang Z, Yang J, et al. Fangcang shelter hospitals: a novel concept for responding to public health emergencies. The Lancet. 2020;395:1305-1314.

21. Municipal Bureau of Commerce. [homepage on the Internet]. Wuhan residents shopping service platform [In Chinese]; 2020 Available from: http://wsqzgzb.cjn.cn/jmgw/index_4960.htm. Accessed April 272020.

22. Zeng L, Zhang Q. Hubei Province receives more than 6.15 million donated materials [In Chinese]. Hubei Daily. Available from: http:// www.hubei.gov.cn/hbfb/bmdt/202001/t20200131_2016717.shtml. Accessed April 27, 2020.

23. Hu J. Deepen the reform of the medical security system in an all-round way, and strive to transform the advantages of the system into governance efficiency [In Chinese]. 2020;4:16-18.

24. Hubei Provincial Government [homepage on the Internet]. Novel coronavirus infection prevention and control of pneumonia. [In Chinese]. 2020. Available from: http://www.hubei.gov.cn/hbfb/ xwfbh/202004/t20200427_2249631.shtml. Accessed April 27, 2020.

25. Zhang D, Wang X, Sun K, Liu M, Qin Y. Working together to rescue small and micro enterprises [In Chinese]. Economic Daily. Available from: http://paper.ce.cn/jjrb/html/2020-02/13/content_412344.htm. Accessed April 27, 2020.

26. General Office of Wuhan Municipal People's Government [homepage on the Internet]. Notice of novel coronavirus pneumonia office on the issue of new crown pneumonia epidemic and supporting the development and operation of small and medium sized enterprises [In Chinese]; 2020. Available from: http://czj.wh.gov.cn/html/xwdt/tzgg/ 202003/t20200309_306362.shtml. Accessed April 27, 2020.

27. Tian $\mathrm{H}$, Liu Y, Li Y, et al. An investigation of transmission control measures during the first 50 days of the COVID-19 epidemic in China. Science. 2020;368(6491):638-642.

28. Xu N. 5G, big data \& cloud computing will be implemented in Wuhan Huoshen Mountain hospital to detect the epidemic situation [In Chinese]. Beijing News. Available from: http://news.sina.com. cn/c/2020-01-26/doc-iihnzhha4808705.shtml. Accessed April 27, 2020.
29. Wuhan City [homepage on the Internet]. Wuhan City Message Board [In Chinese], Available from: http://wsqzgzb.cjn.cn. Accessed April 28, 2020.

30. Yi Q. Mayor's special line 12345 "hears" the people's voice with big data [In Chinese]. Available from: https://www.sohu.com/a/ 324142619_694175. Accessed April 27, 2020.

31. Field P, Susskind L. Dealing with an Angry Public. The Mutual Gains Approach to Resolving Disputes. New York: Free Press; 1996.

32. Rousseau DM, Sitkin SB, Burt RS, Camerer CF. Not so different after all: a cross-discipline view of trust. Acad Manage Rev. 1998;23:393-404.

33. Andersen KG, Rambaut A, Lipkin WI, Holmes EC, Garry RF. The proximal origin of SARS-CoV-2. Nat Med. 2020;26:450-452.

34. Zeng SQ. Study on emerging infectious disease risk communication. Chinese J Health Educ. 2011;27(10):784-786.

35. Cao J, Zhuang C. Government News Release. Nanjing, China: Jiangsu Province People's Press; 2009.

36. Tench R, Yeomans L. Exploring Public Relations. New York: Pearson Education; 2009.

37. Leng Y, Zhai Y, Sun S, et al. Misinformation during the COVID-19 outbreak in China: cultural, social and political entanglements. IEEE Trans Big Data. 2021;1. doi:10.1109/TBDATA.2021.3055758

38. Dudo AD, Dahlstrom MF, Brossard D. Reporting a potential pandemic: a risk-related assessment of avian influenza coverage in U.S. Newspapers Sci Commun. 2007;28(4):429-454.

39. Li W. Hubei: more than 580,000 party members and cadres sink to build the first line of defense for epidemic prevention and control [In Chinese]. Xinhua Net. 2020. Available from: http://www.xinhuanet. com/politics/2020-03/07/c_1125678149.htm. Accessed April 28, 2020.

40. Zhan JV, Juan S. The art of political ambiguity: top-down intergovernmental information asymmetry in China. $J$ Chinese Governance. 2017;2(2):149-168.

41. Sellnow DD, Lane D, Littlefield RS, et al. A receiver-based approach to effective instructional crisis communication. $J$ Contingencies Crisis Manage. 2015;23(3):149-158.

42. Seeger MW. Best practices in crisis communication: an expert panel process. J Appl Commun Res. 2016;34(3):232-244.

43. Jin Y, Austin L, Vijaykumar S, Jun H, Nowak G. Communicating about infectious disease threats: insights from public health information officers. Public Relat Rev. 2019;45(1):167-177.

44. Du HT, Teng L, Zhao ZY. Effects of public management communication in online public opinion about emergent infectious disease: a case study of public opinion in Sina microblog community of MERS. J Intelligence. 2017;36(2):108-114.

45. Koplan JP, Butler-Jones D, Tsang T, Yu W. Public health lessons from severe acute respiratory syndrome a decade later. Emerg Infect Dis. 2013;19:6.

46. Zhang X. The number of complaints of undiagnosed cases of Wuhan Mayor's line decreased by $90 \%$ [In Chinese]. Sina News. Available from: https://news.sina.cn/gn/2020-02-20/detail-iimxxstf2989957.d. html?vt=4\&pos=3. Accessed April 28, 2020.

47. Huynh TLD. Does culture matter: social distancing under the COVID-19 pandemic? Saf Sci. 2020;130:(104872). doi:10.1016/j. ssci.2020.104872

48. Chao M, Xue D, Liu T, Yang H, Hall BJ. Media use and acute psychological outcomes during COVID-19 outbreak in China. J Anxiety Disord. 2020;74. doi:10.1016/j.janxdis.2020.102248

49. Chen Q, Min C, Zhang W, Wang G, Ma X, Evans R. Unpacking the black box: how to promote citizen engagement through government social media during the COVID-19 crisis. Comput Human Behav. 2020;110:106380. doi:10.1016/j.chb.2020.106380

50. Li Y, Chandra Y, Kapucu N. Crisis coordination and the role of social media in response to COVID-19 in Wuhan, China. Am Rev Public Admin. 2020;50(6-7):698-705. doi:10.1177/027507402094 2105 
51. Liao Q, Yuan J, Dong M, Yang L, Fielding R, Lam WWT. Public engagement and government responsiveness in the communications about COVID-19 during the early epidemic stage in China: infodemiology Study on Social Media Data. J Med Internet Res. 2020;22(5):e18796.

52. Chen X. Spaces of care and resistance in China: public engagement during the COVID-19 outbreak. Eurasian Geography Econ. 2020;61 (4-5):435-447. doi:10.1080/15387216.2020.1762690

53. Lohiniva AL, Sane J, Sibenberg K, Puumalainen T, Salminen M. Understanding coronavirus disease (COVID-19) risk perceptions among the public to enhance risk communication efforts: a practical approach for outbreaks, Finland. Euro Surveillance. 2020;25:13.
54. Gollust S E, Nagler R H, Fowler E F. The emergence of COVID-19 in the US: A public health and political communication crisis. J Health Polit Policy Law. 2020;45(6):967-981..

55. Huynh TLD. The COVID-19 containment in Vietnam: what are we doing? J Glob Health. 2020;10:1.

\section{Publish your work in this journal}

Risk Management and Healthcare Policy is an international, peerreviewed, open access journal focusing on all aspects of public health, policy, and preventative measures to promote good health and improve morbidity and mortality in the population. The journal welcomes submitted papers covering original research, basic science, clinical \& epidemiological studies, reviews and evaluations, guidelines, expert opinion and commentary, case reports and extended reports. The manuscript management system is completely online and includes a very quick and fair peer-review system, which is all easy to use. Visit http://www.dovepress.com/testimonials.php to read real quotes from published authors.

Submit your manuscript here: https://www.dovepress.com/risk-management-and-healthcare-policy-journal 